\title{
Choosing Effective Behavior Change Tools ${ }^{\dagger}$
}

\author{
Doug McKenzie-Mohr \\ P. Wesley Schultz
}

\author{
Paper presented at the \\ Behavior, Energy and Climate Change Conference \\ Sacramento, California
}

November, 2012

\footnotetext{
${ }^{\dagger}$ Correspondence regarding this paper should be directed to the authors: Doug McKenzieMohr (dmm@cbsm.com) or Wesley Schultz (wschultz@csusm.edu).
} 


\section{Choosing Effective Behavior Change Tools}

Behavior change is central to the quest for a sustainable future. Traditionally, programs to foster sustainability have relied upon information-intensive campaigns to encourage the adoption of environmentally friendly behaviors (McKenzie-Mohr \& Smith, 1999; McKenzieMohr, 2012; Schultz \& Kaiser, 2012). These campaigns use advertising to disseminate information, and they are often based upon the mistaken assumption that if recipients simply knew or cared more they would change their behavior. While well meaning, these initiatives have been largely ineffective in fostering the adoption of sustainable behaviors (Geller, 1981; McKenzie-Mohr, 2011; Schultz, 2002; Schultz \& Kaiser, 2012). This ineffectiveness has led many environmental program managers to begin utilizing behavior change "tools" from the social sciences in their quest for more effective strategies. While the adoption of these behavior change tools is encouraging, frequently these tools are used in the wrong context or sub-optimally. In this paper, we introduce a variety of behavior change tools and for each, we detail both how and when to use the tool. The paper is written for practitioners, and is intended to assist program managers in developing more effective strategies for fostering sustainable behavior.

Our suggestions are situated within the framework of community-based social marketing (McKenzie-Mohr, 2011; McKenzie-Mohr, Lee, Schultz \& Kotler, 2011). Consequently, prior to discussing how to utilize effective behavior change tools, we first briefly introduce this approach. ${ }^{1}$

\section{Community-Based Social Marketing}

Community-based social marketing (CBSM) is based on five steps: 1) Carefully selecting the behavior(s) to be targeted; 2 ) Identifying the barriers and benefits associated with the selected behavior(s); 3) Designing a strategy that utilizes behavior-change tools to address these barriers and benefits; 4) Piloting the strategy with a small segment of a community; and, finally; 5) Evaluating the impact of the program once it has been broadly implemented. Each of these steps is described below.

- Step 1 - Selecting Behaviors: Whether a program promoting energy or water efficiency, waste reduction, modal transportation shifts, or behavioral changes in other domains, there are a wide array of actions that could be fostered. For instance, in the case of residential energy efficiency a program might encourage the installation of more efficient lighting, turning up the air conditioning temperature, closing blinds to reduce passive heating, or installing a high efficiency showerhead. In fact, over 200 discrete behaviors related to residential energy have been identified (Hargroves \& Desha, 2009). Knowing which behaviors are most important to target is a critical first step in developing effective programs. Selecting

\footnotetext{
${ }^{1}$ See McKenzie-Mohr, D. (2011). Fostering sustainable behavior: An introduction to community-based social marketing (third edition). Gabriola Island, B.C.: New Society.
} 
which behaviors are most useful to target involves two steps. First, a list of behaviors is created that are "non-divisible" and "end-state." For example, adding insulation to a home is really a category of behaviors, which is divisible, based on whether the insulation is to be added to the attic, the walls or the basement. It is important to begin with non-divisible behaviors as the barriers and benefits often differ between apparently very similar behaviors. In addition to being non-divisible, each behavior also needs to be end-state. Frequently, programs encourage non-endstate behaviors, such as the purchase of energy efficient showerheads, and do not accomplish the behavioral change that matters, in this case the installation of the showerhead. Once a list of non-divisible, end-state behaviors has been created, the second step is to scrutinize this list based on the impact, probability and penetration of each behavior. Managers will want to select behaviors that have high impact, high probability of being adopted, and are presently being carried out by relatively few people (low penetration).

- Step 2: Identifying Barriers \& Benefits: The development of effective behavioral change strategies is predicated on both knowing what barriers exist to the adoption of a behavior as well as what would motivate people to act. Research in the social sciences has clearly underscored that these barriers and benefits often differ across behaviors (McKenzie-Mohr, Nemiroff, Beers, \& Desmarais, 1995; Tabanico \& Schultz, 2008). For instance, the barriers to installing a high efficiency showerhead are very different from the barriers associated with carpooling. Uncovering barriers and benefits involves using a combination of techniques, including literature searches to identify past barrier and benefit research, observations, focus groups and surveys. This combination of methods often provides clear guidance as to what inhibits the adoption of a behavior as well as what would motivate action. Barriers may be internal, such as not knowing how to install a high efficiency showerhead, or they may be external, such as there not being a hardware store close by that sells them. Finally, these barriers and benefits often differ across individuals (e.g., renters versus owners). As a consequence, this second step involves not only identifying barriers and benefits, but also determining how they differ across dissimilar groups.

- Step 3: Developing Strategies: Research in the social sciences has identified a number of tools that can be utilized to foster behavioral changes. In the third step, tools such as commitment, prompts, norms, goal setting, and convenience are carefully selected to address identified barriers and benefits.

- Step 4: Piloting: Community-based social marketing strategies are pilot tested prior to broad scale implementation to determine not only their efficacy in changing behavior, but also their cost-effectiveness. Frequently, several strategies are tested against each other with their relative return-on-investment (ROI) being calculated.

- Step 5: Broad-Scale Implementation and Evaluation: Once the effectiveness of a strategy has been demonstrated through a pilot, this strategy is broadly implemented. Ongoing evaluation of this strategy involves direct measurements of 
changes in behavior, resource use or resource quality. These measurements are favored over self-reports of behavioral change or measurements of changes in attitudes or awareness. Evaluation also provides the opportunity for a program to be refined to enhance its effectiveness and potentially reduce delivery costs.

\section{Behavior Change Tools}

In the third step of community-based social marketing, behavior change tools are selected to address the barriers and benefits that were previously identified. Below, we introduce a number of behavior change tools and clarify when and how to use them.

The first consideration in selecting a behavior change tool is the magnitude of the barriers relative to the motivation that a target population has to engage in a behavior (Schultz, in press). A barrier is anything that reduces the probability of a person engaging in the target behavior. Typically, barriers are structural elements that make the behavior more difficult, such as the absence of bicycle lanes on busy city streets. In contrast, benefits refer to a person's reasons for engaging in the target behavior. The sum of the benefits a person associates with the target behavior is their motivation. The heart of CBSM involves reducing barriers and enhancing benefits.

Figure 1 provides a conceptual model of the role of barriers and benefits in changing behavior. In instances where barriers are high, behavior change is most likely when structural changes are made that reduce the difficulty of engaging in the behavior. Indeed, in such cases increasing motivation without addressing barriers is often pointless. However, when barriers are low, behavior change efforts are best aimed at increasing benefits to enhance motivation.

\section{INSERT FIGURE 1}

\section{Commitments}

Imagine receiving a phone call in which you are asked to donate blood. After agreeing to give blood, at the very end of the phone conversation the caller asks, "Can we count on seeing you?" Having already agreed to give blood, not surprisingly, you answer affirmatively. When this very question was appended to the end of blood drive phone calls, the percentage of donors who actually kept their appointments rose from $62 \%$ to $81 \%$ (Lipsitz, Kallmeyer, Ferguson, \& Abas, 1989). Similarly, when individuals who were making restaurant reservations were asked, "Will you please call if you have to cancel?" the percentage of people who did not keep their reservations fell to just $10 \%$ compared to $30 \%$ for those who were simply told, "Please call if you have to cancel."

Commitments work, in part, due to a process that Daryl Bem refers to as self-perception (Bem, 1972). When asked whether we can be counted on to show up for a blood drive, answering affirmatively subtly alters the way that we perceive ourselves. In short, we come 
to see ourselves as the type of person who believes that we have a civic duty to donate blood. As a consequence, it would be inconsistent for us to not subsequently donate. A review of numerous commitment studies indicated that self-perception is the most important factor in determining why commitments work (Burger, 1999).

\section{When to use Commitments}

Commitments are most likely to be effective when an individual is motivated to act, but has not yet engaged in the action. A sizeable amount of research has shown the effectiveness of commitments across many different behaviors, even in situations where the barriers to action are quite high.

\section{How to use Commitments}

As noted, commitments work when an individual comes to see him or herself as the type of person who believes it is important to behave in a particular way. However, if an individual feels at all coerced into making a commitment, the self-perception that underscores commitments is unlikely to occur. Written commitments appear to be more effective than verbal commitments. In a study by Pardini \& Katzev (1983-84), residents were either asked to make a verbal commitment to recycle, a written commitment to recycle, or simply received a pamphlet regarding recycling. Initially both commitment groups recycled more; however, a later follow-up demonstrated that only the group that made the written commitment was still recycling.

Dramatically, when households were asked to make either private or public commitments to conserve natural gas and electricity, only those households who agreed to have their names published in the newspaper actually reduced their natural gas and electricity usage (15\% and 20\%, respectively). Of particular interest is the fact that their names were never even published, and the measurements of natural gas and electricity usage were unobtrusive and conducted a year later (Pallak, Cook, \& Sullivan, 1980).

While public commitments appear more effective than private commitments, those commitments that are public and durable are likely to be particularly effective. Durable commitments, such as placing a sticker on the side or recycling-container, or indicating that a household has engaged in specific energy efficiency actions, such as installing compact fluorescent light bulbs, have the added benefit of fostering both social norms and social diffusion (both of which are discussed subsequently). 


\section{Social Diffusion}

One of the most common reasons for the adoption of a new sustainable behavior is the fact that friends or colleagues have already adopted the action and have told others in their social networks about it. This process, which is referred to as social diffusion, or diffusion of innovations, has been found to influence a broad array of actions, from the installation of programmable thermostats to the uptake of behaviors that protect watersheds. While social diffusion plays a critical role upon the behaviors that we learn about and adopt, it has been strikingly underused to promote sustainable behaviors.

Social diffusion is most likely to occur when the promoted behavior is visible in a community. Curbside recycling, by its very nature is visible. Each time residents put their container at the curbside they are both demonstrating that they believe recycling is important and, therefore normative, but they are also subtly encouraging conversations regarding recycling by making the behavior salient. Note, however, that many energy and water efficiency behaviors have no such saliency as they occur in the privacy of peoples' homes and, consequently, have little opportunity to be observed by others. Fostering social diffusion for low visibility behaviors can often be accomplished by utilizing public and durable commitments. A variety of opportunities exist for leveraging public and durable commitments, but one of the most cost effective residential commitments is to simply ask residents if a sticker can be attached to their curbside recycling container indicating that they have engage in a behavior, such as installing a low-flow showerhead.

\section{Goal Setting}

While the setting of goals is ubiquitous, most personal goals are not achieved. However, research suggests that we are more likely to obtain our goals if we associate them with implementation intentions. For example, when a classroom of university students was told that they could obtain extra credit by writing an essay over the winter holidays, $75 \%$ of the students who were instructed to think about where and when they would write the essay completed it, compared to 33\% for a control group who were not given these instructions (Gollwitzer, 1999). Similarly, when seniors who had just undergone hip or knee surgery were either asked, or not asked, to simply write down where and when they planned to go for a walk this week, the impacts on recovery were astonishing. Those who were instructed to create implementation intentions were able to bathe, stand and get in and out of a car much more quickly than were those who were not asked to write down these details (Orbell \& Sheeran, 2000).

The successful use of implementation intentions is quite straightforward. When an individual has indicated that he or she is interested in engaging in an action, ask him or her to indicate when he or she plans to engage in the action. The simple act of contemplating when a behavior will occur lays the cognitive foundation that precedes a new behavior. 


\section{Social Norms}

Norms refer to the common and accepted behaviors within a group. In essence, norms are what other people do and what they approve of doing. Research by behavioral scientists has been clear in showing that individuals tend to conform to the perceived norm. While there are certainly instances in which individuals want to stand out and deviate from the group, in most circumstances, it is easier and preferable to go with the flow.

Unfortunately, many behavior change campaigns highlight the frequency of undesirable behavior. Awareness campaigns often lament the high rate of consumption or the apparent lack of concern among residents in the region. A recurring theme goes something like this: "Look at this big problem. No one is responding, and no one cares, but you should be different." Messages encouraging individuals to be a "hero" or "star" subtly highlight the fact that few people are doing the desired behavior. While such messages can serve to highlight the severity of a problem, they also convey a normative message about what other people are doing.

\section{How to use norms}

The social norm strategy for behavior change involves highlighting the large number of people who already do the behavior and/or approve of the behavior. For example, Nolan et al. (2008) used energy conservation messages that explicitly highlighted the percentage of residents in a community who engaged in specific actions, such as using fans instead of air conditioning to stay cool in the summer. The results showed that these normative messages were effective at reducing electricity consumption by $10 \%$, relative to a control group. Similarly, several recent campaigns have highlighted the number of pledges received on a website, or the large number of volunteers at a local event. Finally, testimonials from supporters can help to create a social norm (Tabanico \& Schultz, 2008).

An important, but often overlooked, consideration in crafting normative messages is the referent group. Normative messages involve communications about the behavior of "others," but typically the referent is not clearly defined. Research suggests that outgroup referents have a tendency to produce distancing effects. That is, when normative information is provided about individuals from a disliked group, the behavioral tendency is to engage in the opposite pattern of actions. Thus, it is important to avoid using normative information about extreme groups, zealots, or fervent supporters. Instead, the stronger approach is to use social identities, such as neighborhoods or cities, or even to allow individuals to customize the referent through the use of social media or interactive web applications.

\section{When to use social norms}

Social norms approaches have been successfully applied across a range of behaviors, from energy, to water, to waste and recycling. One of the most encouraging findings from these applications is that norms are most effective among people who are not already motivated to engage in the behavior. In fact, in the energy domain norms messaging and normative feedback have been found to produce the largest behavioral changes among the individuals 
who are the highest users. Thus, the norms approach is appropriate for a target audience that is low in motivation.

\section{Prompts}

Forgetting is a common barrier to individuals engaging in sustainable behaviors. Actions as diverse as maintaining correct tire air pressure, turning off lights, and using cloth shopping bags are frequently not engaged in simply because people forget. Forgetting to engage in some repetitive behaviors can be addressed through technical solutions, such as the use of programmable thermostats, motion sensitive lighting, and smart strips that automatically turn off computer equipment when not in use. Unfortunately, few repetitive actions have low-cost technological fixes. In these cases, prompts are necessary to overcome forgetting.

Prompts are simply memory aids that are presented in close proximity to the repetitive behavior. These aids may be visual or auditory. For example, community recycling containers with tops that visually indicate what types of recyclables are accepted have been found to markedly reduce contamination. Similarly, prompts that provide normative information on reusing towels in hotels have been found to substantially increase reuse.

The guidelines for utilizing prompts are straightforward. Prompts need to be noticeable and self-explanatory and presented in close proximity to the behavior. Finally, prompts should target positive behaviors rather than encouraging the avoidance of negative behaviors. There are two reasons for focusing on beneficial rather than harmful behaviors. First, telling people not to do something has the deleterious effect of educating those who are unaware of a negative behavior that about an undesirable behavior exists. Second, $\mathrm{b}$ focusing on a positive behaviors we are providing information on what behaviors are desirable rather than simply telling someone not to do something (e.g., reusing your towel is appropriate and approved of by others).

\section{Incentives}

Behavioral research is clear in showing that offering a reward for a behavior can increase its frequency. In addition, from a CBSM perspective, if cost is a barrier to the target behavior, then offering an incentive can reduce the difficulty of the action. Incentives have been widely used as a behavior change tool, and in fact, individuals often point to incentives as primary reason for engaging in the behavior.

Incentives can take a variety of forms, but they universally involve a desirable consequence following the behavior. Examples of incentive strategies include direct rebates for purchasing an energy efficient appliance, or discounted prices for an LED light bulb. However, incentive strategies can also involve increasing costs for an undesirable behavior, such as higher prices for gasoline, or per-tonnage charges for trash while recyclables are collected for free. Not surprisingly, research has shown that incentives can exert a powerful 
influence on behavior and the larger the incentive or disincentive, the greater the amount of behavioral change.

While incentives can produce large changes in behavior, they also come with a number of serious side effects. The first is durability. Repetitive behaviors that are changed through incentives typically revert back once the incentive is removed (Schultz \& Kaiser, 2012). In fact, there is also evidence for overjustification effects, wherein the behavior drops below the initial levels once the incentive is removed (Deci, Koestner, \& Ryan, 1999). A second limitation is the specificity of the change. Behaviors that are changed through incentives generally do not spillover into other domains (Schultz, 2010). For example, offering a large incentive for the purchase of energy efficient lightbulbs will generally not spill over into other energy efficiency behaviors, like using a switchable powerstrip or turning off computers when leaving the office. In fact, there are documented instances of rebound effects, wherein a person who installs a more efficient appliance uses it more often because it is more efficient. Due to the side effects associated with incentives, they should be used sparingly, and they typically work best in instances where cost operates as a barrier to the action.

\section{Feedback}

Feedback is essential for reaching a goal. Without updated information about our behavior, it is difficult (if not impossible) to achieve a desired outcome. Typically, feedback provides an individual with measures of a physical characteristic, such as consumption of electricity, gallons of water consumed, or miles-per-gallon.

But feedback alone is rarely sufficient to change behavior. While feedback is essential for reaching a goal, it is only effective when the person wants to achieve the outcome (Schultz, 2010). As a result, feedback strategies need to couple the information with a goal-for example, saving money, winning in a competition, reducing carbon emissions, or beating one's personal best. In the case of residential electricity consumption, there has been a sizable investment in feedback systems linked to smart meters. Unfortunately, the research findings with regard to feedback have been mixed. Providing residents with $\mathrm{kWh}$ consumption information can produce a reduction in consumption, but the effect is typically limited to individuals who were already motivated to use less.

While the research findings with regard to feedback are mixed, there is clear evidence that coupling the feedback with a meaningful referent can produce durable changes in behavior. One example of a meaningful referent is normative information, and OPOWER has successfully leveraged normative feedback to produce reductions in residential energ consumption (Allcott \& Rogers, 2012; Ayres, Raseman, \& Shih, 2009). Another commonly used referent is cost, whereby residents are provided with feedback about their current consumption, along with the associated cost. While financial referents can be effective, the approach tends to work best for individuals who are concerned about the high cost of their 
utility bills. In instances where the individual does not pay their bill, or where the costs associated with specific behaviors are low, the approach tends to be ineffective.

\section{Convenience}

One of the hallmarks of a CBSM campaign is the focus on reducing barriers. While barriers can take a variety of forms, they are typically associated with an increased degree of difficulty. Examples include the extra effort required to sort recyclable material into separate bins, the extra time required for a computer to power-up after being shut down, or the physical exertion required to ride a bike to work instead of driving a car. In many instances, the "green" behavior is more difficult than the status quo.

If the target behavior is extremely difficult, the critical first step to promoting behavior change is to make it more convenient. If the target behavior can be made more convenient than the alternative, behavior change will naturally follow. Consider the case of the default setting on a washing machine. Many high efficiency washing machines are programmed with warm water as the default setting. To use the more efficient cold-water option requires changing the settings for every load of wash. An easy solution is to use cold as the default, in which case switching to hot becomes the more difficult option.

As shown in Figure 1, barriers and motivation can have independent effects on behavior. When barriers are extremely high, very few individuals will have sufficient motivation to overcome the obstacles. However, when the barriers are low especially relative to other options, even individuals with very low motivation will choose them. Dedicated carpool lanes provide a good example of reducing the barriers, relative to the alternative action. Similarly, providing traffic privileges for cyclists can make riding a bike to work more convenient than driving a car. Or using master switches on hotel rooms where guests activate the power in the room with their key when they arrive can reduce the difficulty of turning off the lights and the air conditioning when they leave.

\section{Program Examples}

Three examples are provided of community-based social marketing programs where the behavior change tools utilized closely match the identified barriers and benefits. The include: 1) persuading anglers to release rather than consuming contaminated fish; 2) encouraging motorists to not idle their engines when parked; and 3) prompting employees to turn off their computers and monitors when leaving work.

\section{What's the Catch}

The Palos Verdes Shelf is a coastal area in close proximity to Long Beach, California. Over a period of nearly forty years several companies discharged an estimated 110 tons of DDT 
and 10 tons of PCBs into the sewer system, resulting in these contaminants being discharged into the ocean, settling into the sediment on the ocean floor over an area of 17 square miles. As a result, fish caught within this area have a higher likelihood of being contaminated, especially bottom-feeders like white croaker which have a relatively small range and digestive systems which deal ineffectively with these contaminants. To reduce the potential health effects associated with eating contaminated white croaker, the U.S. Environmental Protection Agency used community-based social marketing to develop an effective outreach campaign.

In the Palos Verdes Shelf coastal area, angling often occurs from the nine regional piers. To identify the barriers and benefits, intercept interviews were conducted with anglers in this area (Jonick et al, 2010). The interviews also helped to clarify what anglers were presently doing when they caught white croaker. That is, were they releasing the fish, taking it home to consume themselves, or giving it to others to consume? Participants in the intercept survey were ethnically diverse, with the majority Latino (52\%) and predominantly male (90\%). The intercept surveys identified that not knowing that white croaker was contaminated was the most significant reason for not releasing the fish. Further, $73 \%$ of anglers reported that a health-related message would be motivating and $70 \%$ indicated that a message related to the health of children would be a particularly strong motivator. This research led to the development of a "Tip Card" which showcased a physician examining a child and contained the following message:

"Protect your health and the health of your children: Join with other fishermen and release white croaker back into the ocean to avoid consuming contaminated fish." In addition to this message, the tip card included a photo of a white croaker to make it easier for anglers to identify the fish.

The intervention occurred on one pier while another served as the control area. The program began with baseline observations, which involved identifying and counting the fish in an angler's possession when leaving the pier. The program used pier outreach workers to deliver in-person messages to anglers about how white croakers became contaminated and followed with a recommendation that anglers release any white croaker that they catch. Anglers were also given a tip card which reinforced the message and helped them to identify white croaker. Prior to and following this intervention, surveys were conducted with anglers as they left the pier. This survey involved counting the overall number of fish that they caught, the number of white croaker caught, and asking anglers to identify white croaker from a card that depicted a number of species of fish. They were also asked what they intended to do with the white croakers that were in their fishing bucket.

The physical inspection of the buckets demonstrated that at the intervention pier, there was a 93\% reduction in the number of white croaker leaving the pier, while at the control pier there was effectively no change. The intervention also positively influenced selfreports of what anglers did when they caught white croaker. These self-reports indicated that catch and release increased significantly, while self-consumption or giving white croaker to family or friends reduced substantially. 


\section{Turn it Off}

Engine idling in Canada is ubiquitous. Canadians idle their engines an average of eigh minutes a day (Phase 5 Consulting, 1988). This unnecessary engine idling contributes to local air pollution and to greenhouse gas emissions. In a program to reduce engine idling, a pilot project was conducted in Toronto at schools and Toronto Transit Commission "Kiss and Ride" parking lots. Both settings are locations in which engine idling is frequent. At schools, parents and guardians often idle their engines when dropping off or picking up children, whereas at Kiss-and-Ride parking lots, partners frequently idle their engine while waiting for a loved one to return on a train. Baseline measurements indicated that at these two locations vehicles were left idling $53 \%$ of the time.

To identify the barriers and benefits to engine idling, focus groups and a telephone survey were conducted. This research indicated that Canadian motorists forget to turn their engines off, believe it is fuel efficient to wait longer than three minutes before turning their engines off, and that repeatedly turning their engines off would hurt their motors (McKenzie-Mohr \& Associates \& Lura Consulting, 2001). When benefits were explored the most important reported reason for turning off their engines was to enhance air local air quality.

Two community-based social marketing strategies were pilot tested to see which one could most cost effectively reduce engine idling. In one strategy, signs were placed in the Kiss and Ride and school parking lots reminding motorists to turn their engines off. Unobtrusive measurements of engine idling before and after the signs were installed demonstrated that the use of signs alone did not reduce idling.

In the other pilot strategy, the same signs were also used. However, in addition motorists were also spoken to personally, while prompts and commitments were utilized.

As noted above, the signs by themselves did not reduce engine idling. However, the combination of the signs, plus personal contact, prompts and commitments significantly altered the frequency of engine idling. Despite the fact that the conversations with motorists were only approximately a minute in duration., overall, engine idling was reduced by $32 \%$ and the duration of idling by a remarkable $73 \%$. Based on this pilot, Natural Resources Canada created a website which provided information on how to deliver effective anti-idling programs along with downloadable resources (e.g., window stickers, parking lots signs, etc.). As a consequence of providing these turnkey resources, some 200 Canadian communities have now delivered anti-idling programs based on this success of this pilot (Natural Resources Canada, 2010).

\section{Taking Off? Tur u Off}

Desktop computers are a necessity in today's office work environment. But many computers remain on, even when not in use. These inactive computers and monitors 
continue to draw power, albeit at a reduced rate. The typical computer (CPU) uses 100 watts/hour in "sleep" mode, and a 19" LCD monitor uses 25 watts/hour in sleep mode. While seemingly small, these loads add up, and assuming 16 hours of inactivity per day (i.e., an 8-hour workday), this results in a yearly total of $582 \mathrm{kWh}$ for the CPU and $146 \mathrm{kWh}$ for the monitor-that's for one computer, when not in use. Turning off computers and monitors when not in use provides a clear end-state, nondivisible behavior.

Turning off computers at the end of the workday was the target of a CBSM campaign conducted by the Urban Sustainability Director's Network. The campaign was conducted in government offices in Santa Clara County, CA; Frederick County, MD; and Columbia, MO. Barriers and benefits were identified through employee focus groups, interviews with IT staff, and a brief web survey of employees. The identified barriers were lack of knowledge that monitors continued to draw power when in sleep mode, the long start up times for computers that were completely powered off, forgetting, and lack of knowledge about internal policies for power management. The perceived benefits were reduced environmental impact and saving money for the organization.

The resulting campaign involved removing barriers, highlighting financial savings to the organization, personal contact, a commitment strategy, and a prompt. The program begin with an initial email to employees communicating the existing IT policy for powering down computers and monitors at the end of the workday. This was followed with an in-person communication from staff and peers within the organization. The in-person communication included a short informational flyer, and a signed commitment to turn off computers and monitors. The signed commitment was then affixed to the lower left of the monitor, serving as both a prompt and to make the commitment public and durable. The program was implemented in several departments within each governmental organization, and the results were compared to control departments who just received the email from IT.

At the end of each workday, all computers and monitors across the organizations were observed and their status was recorded. Baseline observations showed that across all three organizations, computers were turned off $58 \%$ of the time, and monitors $21 \%$. For employees in the control condition (who received only the email), there were significant changes across time: computer turn off rates during the post-treatment period were $64 \%$ and the monitors were $23 \%$. However, for employees that received the full program (email, plus commitment, plus prompt) the turn off rates in the post-treatment period were $72 \%$ for computers, and $53 \%$ for monitors. These results showed that the program was particularly effective at increasing turn off rates for monitors, which more than doubled as a result of the program. The templates for the campaign materials are freely available to USDN members interested in implementing a computer turn off program. 


\section{References}

Allcott, H., \& Rogers, T. (2012). The short-run and long-run effects of behavioral interventions: Experimental evidence from energy conservation. National Bureau of Economic Research. Cambridge, Massachusetts. Working paper, available online at: http://www.nber.org/papers/w18492.

Ayres, I., Raseman, S., \& Shih, A. (2009). Evidence from two large field experiments that peer comparison feedback can reduce residential energy use. National Bureau of Economic Research. Cambridge, Massachusetts. Working paper, available online at: http://www.nber.org/papers/w15386.

Bem, D.J. (1972). Self-perception theory. In L. Berkowitz (Ed.), Advances in Experimental Social Psychology (Vol. 6, pp. 63-108). New York: Academic.

Burger, J. M. (1999). The foot-in-the-door compliance review: A multi-process analysis and review. Personality and Psychology Review, 3(4), 303-325.

Cioffi, D. \& Garner, R (1996). On Doing the Decision: Effects of Active versus Passive Choice on Commitment and Self-Perception. Personality and Social Psychology Bulletin, 22 133-147.

Deci, E., Koestner, R., \& Ryan, R. (1999). A meta-analytic review of experiments examining the effects of extrinsic rewards in intrinsic motivation. Psychological Bulletin, 125, 627-668.

Geller, E.S. (1981). Evaluating energy conservation programs: Is verbal report enough? Journal of Consumer Research, 8, 331-335.

Gollwitzer,P. M. (1999). Implementation intentions: Strong effects of simple plans. American Psychologist, 54(7), 493-503.

Hargroves, K., Desha, C. \& McKenzie-Mohr, D. (2009). Personal communication.

Jonick, T., Anderson, E., Lin, S., Bruni, C., Schultz, W., Groner, S., \& Orrala, F. (2010). What's the catch? Reducing consumption of contaminated fish among anglers. Social Marketing Quarterly, 16(1), 33-51.

Phase 5 Consulting Group (1998). Research related to behavior that impacts fuel consumption. Natural Resources Canada: Ottawa, Canada.

Lipsitz, A., Kallmeyer, K., Ferguson, M., \& Abas, A. (1989). Counting on blood donors: Increasing the impact of reminder calls. Journal of Applied Social Psychology, 19 1057-1067.

McKenzie-Mohr, D. (2011). Fostering sustainable behavior: An introduction to communitybased social marketing (3rd Edition). Gabriola Island, B.C.: New Society.

McKenzie-Mohr, D., Lee, N., Schultz, W., \& Kotler, P. (2011). Social marketing to protect the environment: What works. Thousand Oaks, CA: Sage. 
McKenzie-Mohr \& Associates \& Lura Consulting (2001). Turn it Off: Reducing vehicle engine idling. Environment Canada.

McKenzie-Mohr, D., Nemiroff, L.S., Beers, L. \& Desmarais, S. (1995). Determinants of responsible environmental behavior. Journal of Social Issues, 51, 139-156.

Natural Resources Canada (2010). Toward and idle-free nation: The evolution of Canada's idle-free initiative. Natural Resources Canada: Ottawa, Canada.

Orbell, S. \& Sheeran, P. (2000), Motivational and volitional processes in action initiation: A field study of the role of implementation intentions. Journal of Applied Social Psychology, 30, 780-797

Pallak, M.S., Cook, D.A., \& Sullivan, J.J. (1980). Commitment and energy conservation. In L. Bickman (Ed.), Applied Social Psychology Annual (pp. 235-253). Beverly Hills, CA: Sage.

Pardini, A.U., \& Katzev, R.D. (1983-84). The effects of strength of commitment on newspaper recycling. Journal of Environmental Systems, 13, 245-254.

Schultz, P. W. (2002). Knowledge, education, and household recycling: Examining the knowledge-deficit model of behavior change. In T. Dietz \& P. Stern (Eds.), New tools for environmental protection (pp. 67-82). Washington DC: National Academy of Sciences.

Schultz, P. W., \& Kaiser, F. G. (2012). Promoting proenvironmental behavior. In S. Clayton (Ed.), Handbook of environmental and conservation psychology (pp. 556-580). Oxford University Press.

Schultz, P. W. (in press). Strategies for promoting proenvironmental behavior: Lots of tools but few instructions. European Psychologist [Special Issue on Sustainability].

Schultz, P. W. (2010). Making energy conservation the norm. In K. Ehrhardt-Martinez \& J. Laitner (Eds.), People-centered initiatives for increasing energy savings. Online book available at: http://www.aceee.org/people-centered-energy-savings.

Tabanico, J., \& Schultz, P. W. (2008). Community-based social marketing and behavior change. In A. Cabaniss (Ed.), Handbook on household hazardous waste (pp. 133-157). Lanham, MD: Government Institutes Press. 
Figure 1: A Conceptual representation of the role of motivation and barriers in social marketing campaigns.
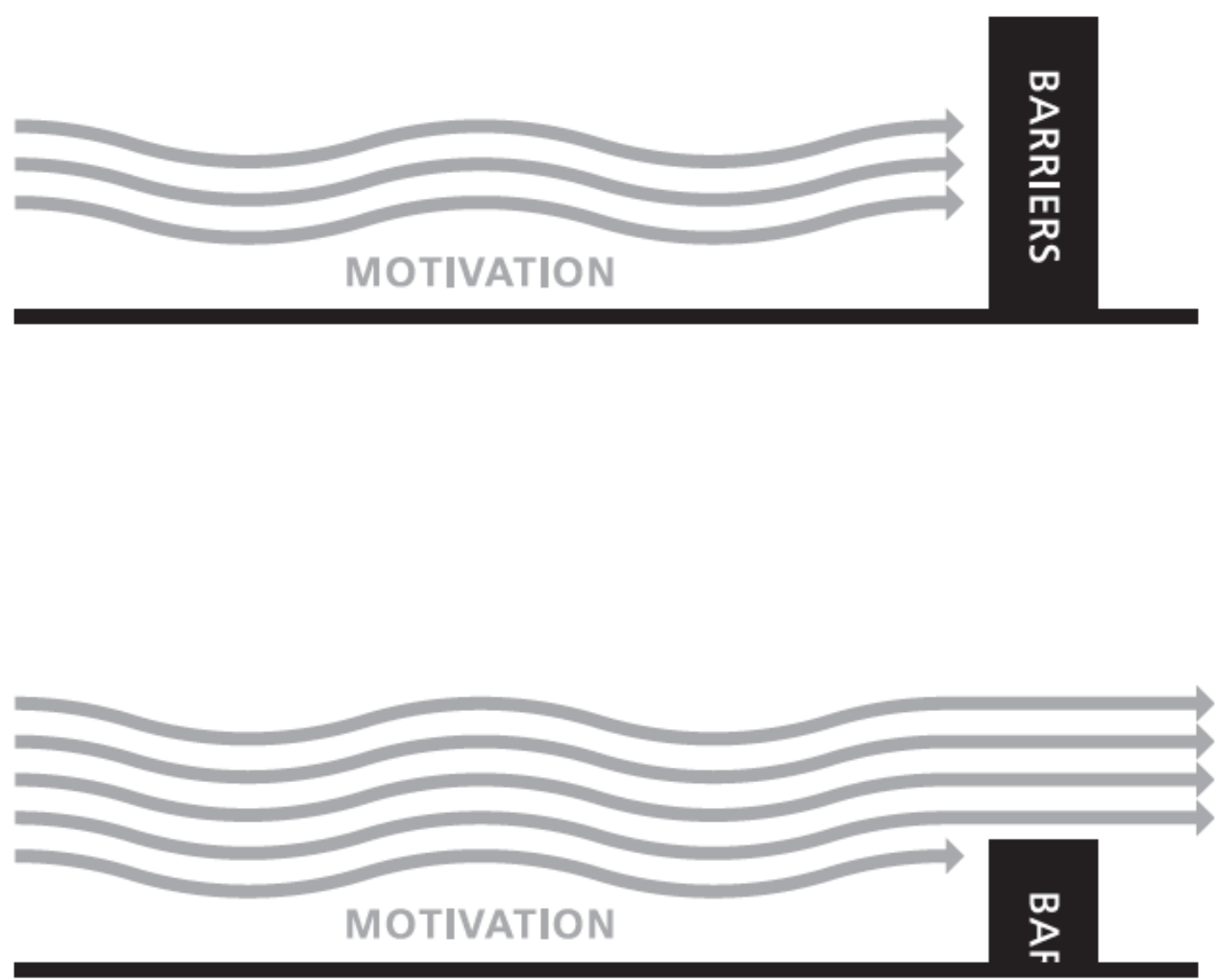

(C) PW Schultz, 2012. Reprinted with permission. 